\title{
A noncompeting pair of human neutralizing antibodies block COVID-19 virus binding to its receptor ACE2
}

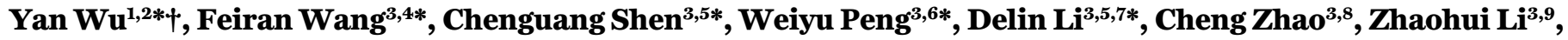 \\ Shihua $\mathrm{Li}^{3}$, Yuhai Bì ${ }^{3,10}$, Yang Yang ${ }^{5}$, Yuhuan Gong, ${ }^{3,10}$, Haixia Xiao ${ }^{7}$, Zheng Fan ${ }^{3}$, Shuguang Tan ${ }^{3}$, Guizhen Wu ${ }^{11}$, \\ Wenjie Tan ${ }^{11}$, Xuancheng Lu ${ }^{12}$, Changfa Fan ${ }^{13}$, Qihui Wang ${ }^{3}$, Yingxia Liu ${ }^{5}$, Chen Zhang', Jianxun $\mathbf{Q i}^{3}$, \\ George Fu GaO ${ }^{3} \uparrow$, Feng Gao ${ }^{7} \uparrow$, Lei Liu ${ }^{5} \uparrow$
}

${ }^{1}$ Department of Pathogen Microbiology, School of Basic Medical Sciences, Capital Medical University, Beijing, China. ${ }^{2}$ Research Network of Immunity and Health (RNIH), Beijing Institutes of Life Science, Chinese Academy of Sciences, Beijing, China. ${ }^{3}$ CAS Key Laboratory of Pathogenic Microbiology and Immunology, Institute of Microbiology, Chinese Academy of Sciences (CAS), Beijing, China. ${ }^{4}$ School of Life Sciences, University of Science and Technology of China, Hefei, Anhui, China. ${ }^{5}$ Shenzhen Key Laboratory of Pathogen and Immunity, Shenzhen Third People's Hospital, Shenzhen, China. ${ }^{6}$ College of Veterinary Medicine, China Agricultural University, Beijing, China. ${ }^{7}$ Laboratory of Protein Engineering and Vaccines, Tianjin Institute of Industrial Biotechnology, Chinese Academy of Sciences (CAS), Tianjin, China. ${ }^{8}$ Shanxi Academy of Advanced Research and Innovation, Taiyuan, China. ${ }^{9}$ University of Chinese Academy of Sciences, Beijing, China. ${ }^{10}$ Center for Influenza Research and Early Warning, Chinese Academy of Sciences (CASCIRE), Beijing, China. ${ }^{11} \mathrm{NHC}$ Key Laboratory of Biosafety, National Institute for Viral Disease Control and Prevention, Chinese Center for Disease Control and Prevention, Beijing, China. ${ }^{12}$ Laboratory Animal Center, Chinese Center for Disease Control and Prevention, Beijing, China. ${ }^{13}$ Division of Animal Model Research, Institute for Laboratory Animal Resources, National Institutes for Food and Drug Control, Beijing, China.

*These authors contributed equally to this work.

†Corresponding author. Email: wuy@biols.ac.cn (Y.W.); gaofeng@tib.cas.cn (F.G.); gaof@im.ac.cn (G.F.G.); liulei3322@aliyun.com (L.L.)

Neutralizing antibodies could be antivirals against COVID-19 pandemics. Here, we report isolation of four human-origin monoclonal antibodies from a convalescent patient, all of which display neutralization abilities. B38 and H4 block the binding between virus S-protein RBD and cellular receptor ACE2. A competition assay indicates their different epitopes on the RBD, making them a potential virus-targeting MAb-pair to avoid immune escape in future clinical applications. Moreover, a therapeutic study in a mouse model validated that these antibodies can reduce virus titers in infected lungs. The RBD-B38 complex structure revealed that most residues on the epitope overlap with the RBD-ACE2 binding interface, explaining the blocking effect and neutralizing capacity. Our results highlight the promise of antibodybased therapeutics and provide a structural basis for rational vaccine design.

The COVID-19 caused by the novel coronavirus COVID-19 virus has become a pandemic. The virus has spread worldwide, causing fever, severe respiratory illness and pneumonia $(1,2)$. Phylogenetic analysis indicates that the virus is closely related to severe acute respiratory syndrome coronavirus (SARS-CoV) (3-5), but it appears to be more easily transmitted from person to person (6). To date, no specific drugs or vaccines are available.

COVID-19 virus belongs to the betacoronavirus genus, which includes five pathogens that infect humans $(7,8)$. Among them, SARS-CoV and Middle East respiratory syndrome coronavirus (MERS-CoV) are two highly pathogenic viruses. As with other coronaviruses, the spike glycoprotein (S) homotrimer on the COVID-19 virus surface plays an essential role in receptor binding and virus entry. The $S$ protein is a class I fusion protein-each S protomer consists of S1 and S2 domains (9) with the receptor binding domain (RBD) located on the S1 domain (8). Previous studies revealed that the COVID-19 virus, similarly to SARS-CoV, uses the ACE2 receptor for cell entry $(3,10-13)$. Numerous neutralizing antibodies have been found targeting the RBDs of SARS-CoV or MERS (14-16). Therefore, screening for neutralizing antibodies that target the COVID-19 virus RBD is a priority.

We expressed COVID-19 virus RBD protein as bait to isolate specific single memory B-cells from COVID-19 patient peripheral blood mononuclear cells (PBMCs). The variable regions encoding the heavy and light chain were each amplified from separate single B cells, and then were cloned into a pCAGGS vector with the constant region to produce IgG1 antibodies as described previously (17). Seventeen paired B cell clones were amplified, three of which were identical (B5, B59 and H1). To identify the antibody binding abilities, the plasmids containing the paired heavy and light chains were cotransfected into HEK 293T cells for monoclonal antibody (MAbs) production. The supernatants were then screened for binding to the RBD by bio-layer interferometry (BLI). An irrelevant anti-SFTSV Gn antibody and a SARS specific antibody were used as controls (18). The supernatants from four different antibodies (B5, B38, H2 and H4) bound to COVID19 virus RBD, but not to SARS-CoV RBD (fig. S1), suggesting 
the epitopes of the two RBDs are immunologically distinct. The usage of heavy chain $\left(\mathrm{V}_{\mathrm{H}}\right)$ and light chain $\left(\mathrm{V}_{\mathrm{L}}\right)$ variable genes in these four antibodies are listed in table S1.

The dissociation constants $\left(K_{d}\right)$ for the four antibodies binding to COVID-19 virus RBD, measured using surface plasmon resonance (SPR) ranged from $10^{-7}$ to $10^{-9} \mathrm{M}$ (Fig. 1, A to D). We next studied the neutralizing activities of these four antibodies against COVID-19 virus (BetaCoV/Shenzhen/SZTH-003/2020). All exhibited neutralizing activities, with $\mathrm{IC}_{50}$ values ranging from $0.177 \mu \mathrm{g} / \mathrm{ml}$ to $1.375 \mu \mathrm{g} / \mathrm{ml}$ (Fig. 2, A to D). Cocktail B38 and H4 exhibit synergetic neutralizing ability, even in the presence of a higher titer of virus (Fig. 2E).

To evaluate the ability of each antibody to inhibit binding between RBD and ACE2, we performed a competition assay using BLI and a blocking assay using fluorescence-activated cell sorting (FACS). For the BLI assay, streptavidin biosensors labeled with biotinylated RBD were saturated with antibodies, and then the test antibodies were flowed through in the presence of soluble ACE2. B38 and H4 showed complete competition with ACE2 for binding to RBD. In contrast, B5 displayed partial competition, while $\mathrm{H} 2$ did not compete with ACE2 for RBD binding (Fig. 1, E to H). The blocking assay by FACS presented the same result (Fig. 1I). To determine whether B38 and H4 target the same epitope, we performed an epitope competition assay by BLI. The Ni-NTA sensor labeled with the RBD was saturated with B38 IgG and H4 IgG was flowed through, or the sensor was first saturated with $\mathrm{H} 4$ IgG and B38 IgG was flowed through. Although RBD was saturated with the first antibody, the second antibody could still bind to RBD, but with some inhibition. This suggests that B38 and $\mathrm{H} 4$ recognize different epitopes on RBD with partial overlap (Fig. 1, J and K).

To explore the protection efficacy of $\mathrm{B} 38$ and $\mathrm{H} 4$ against challenge with COVID-19 virus in vivo, hACE2 transgenic mice were administered a single dose of $25 \mathrm{mg} / \mathrm{kg}$ of $\mathrm{B} 38$ or H4 12 hours after viral challenge. The body weight of B38 group decreased slowly and recovered at 3 days post infection (dpi) compared with the PBS control group and the H4 group (Fig. 3A). The number of viral RNA copies in the lung were also measured at 3 dpi. The RNA copies of both B38 group and $\mathrm{H} 4$ group were significantly lower than the PBS group, with a reduction of $32.8 \%$ and $26 \%$, respectively (Fig. 3B). These results show the same trends as the neutralization abilities. Histopathological examination indicated that severe bronchopneumonia and interstitial pneumonia can be observed in the mice of PBS control group, with edema and bronchial epithelia cell desquamation and infiltration of lymphocytes within alveolar spaces (Fig. 3, C and F). Mild bronchopneumonia was observed in the H4 group (Fig. 3, E and $\mathrm{H}$ ), while no lesions were observed in the B38 group (Fig. 3, D and G).
Consistent with the binding affinity between RBD and B38 or H4, stable complexes were obtained in both RBD-B38 and RBD-H4 mixtures (fig. S2). Complex crystal structure of RBD-B38 Fab was solved at $1.9 \AA$ A resolution (table S2). Three complementarity-determining regions (CDRs) on the heavy chain and two CDRs on the light chain are involved in interaction with RBD (Fig. 4, A, B, and G to K). The buried surface area of heavy and light chain on the epitope is $713.9 \AA$ and $497.7 \AA$, respectively. There are 36 residues in the RBD involved in the interaction with $\mathrm{B} 38$, in which 21 residues and 15 residues interact with heavy and light chain, respectively (table S3 and Fig. 4B). Sequence alignment indicates that only 15 of the 36 residues in the epitope (defined as residues buried by B38) are conserved between COVID-19 virus and SARSCoV (Fig. 4, D to F, and fig. S3). Notably, most contacts in the interface between B38 and RBD are hydrophilic interactions (table S4). Water molecules play important role in the binding between COVID-19 RBD and B38 (Fig. 4, G and I to K). These difference explain the B38 specific binding to COVID19 rather than SARS-CoV.

To explore the structural basis for B38 blocking the interaction between COVID-19 virus RBD and ACE2, the complex structures of RBD/B38-Fab and RBD/hACE2 were superimposed. Both the $\mathrm{V}_{\mathrm{H}}$ and $\mathrm{V}_{\mathrm{L}}$ of $\mathrm{B} 38$ would in sterically hinder ACE2 binding (Fig. 4C). Notably, the RBD in B38-bound form and hACE2-bound form have no significant conformational changes with a $\mathrm{C} \alpha$ root mean squared deviation (RMSD) of $0.489 \AA$ (for 194 atoms). Further analysis indicated that 18 of the 21 amino acids on the RBD are involved in binding both B38 and ACE2 (Fig. 4D), which explains why B38 abolishes the binding between COVID-19 virus RBD and the receptor.

As the COVID-19 outbreak continues to spread, characterization of the epitopes on the COVID-19 virus RBD will provide valuable information for vaccine development. Furthermore, the molecular features of the neutralizing antibody targeting epitopes are helpful for the development of small molecule or peptide drugs/inhibitors. The neutralizing antibodies themselves are also promising candidates for prophylactic and therapeutic treatment against COVID-19 virus.

\section{REFERENCES AND NOTES}

1. N. Zhu, D. Zhang, W. Wang, X. Li, B. Yang, J. Song, X. Zhao, B. Huang, W. Shi, R. Lu, P. Niu, F. Zhan, X. Ma, D. Wang, W. Xu, G. Wu, G. F. Gao, W. Tan; China Novel Coronavirus Investigating and Research Team, A novel coronavirus from patients with pneumonia in China, 2019. N. Engl. J. Med. 382, 727-733 (2020). doi:10.1056/NEJMoa2001017 Medline

2. C. Wang, P. W. Horby, F. G. Hayden, G. F. Gao, A novel coronavirus outbreak of global health concern. Lancet 395, 470-473 (2020). doi:10.1016/SO140$\underline{6736(20) 30185-9}$ Medline

3. P. Zhou, X.-L. Yang, X.-G. Wang, B. Hu, L. Zhang, W. Zhang, H.-R. Si, Y. Zhu, B. Li, C.L. Huang, H.-D. Chen, J. Chen, Y. Luo, H. Guo, R.-D. Jiang, M.-Q. Liu, Y. Chen, X.-R. Shen, X. Wang, X.-S. Zheng, K. Zhao, Q.-J. Chen, F. Deng, L.-L. Liu, B. Yan, F.-X. Zhan, Y.-Y. Wang, G.-F. Xiao, Z.-L. Shi, A pneumonia outbreak associated with a new coronavirus of probable bat origin. Nature 579, 270-273 (2020). doi:10.1038/s41586-020-2012-7 Medline 
4. W. Tan, X. Zhao, X. Ma, W. Wang, P. Niu, W. Xu, G. F. Gao, G. Wu, A novel coronavirus genome identified in a cluster of pneumonia cases-Wuhan, China 2019-2020. China CDC Weekly 2, 61-62 (2020).

5. R. Lu, X. Zhao, J. Li, P. Niu, B. Yang, H. Wu, W. Wang, H. Song, B. Huang, N. Zhu, Y. Bi, X. Ma, F. Zhan, L. Wang, T. Hu, H. Zhou, Z. Hu, W. Zhou, L. Zhao, J. Chen, Y. Meng, J. Wang, Y. Lin, J. Yuan, Z. Xie, J. Ma, W. J. Liu, D. Wang, W. Xu, E. C. Holmes, G. F. Gao, G. Wu, W. Chen, W. Shi, W. Tan, Genomic characterisation and epidemiology of 2019 novel coronavirus: Implications for virus origins and receptor binding. Lancet 395, 565-574 (2020). doi:10.1016/S01406736(20)30251-8 Medline

6. J. F. Chan, S. Yuan, K.-H. Kok, K. K.-W. To, H. Chu, J. Yang, F. Xing, J. Liu, C. C.-Y. Yip, R. W.-S. Poon, H.-W. Tsoi, S. K.-F. Lo, K.-H. Chan, V. K.-M. Poon, W.-M. Chan, J. D. Ip, J.-P. Cai, V. C.-C. Cheng, H. Chen, C. K.-M. Hui, K.-Y. Yuen, A familial cluster of pneumonia associated with the 2019 novel coronavirus indicating person-toperson transmission: A study of a family cluster. Lancet 395, 514-523 (2020). doi:10.1016/S0140-6736(20)30154-9 Medline

7. F. Wu, S. Zhao, B. Yu, Y.-M. Chen, W. Wang, Z.-G. Song, Y. Hu, Z.-W. Tao, J.-H. Tian, Y.-Y. Pei, M.-L. Yuan, Y.-L. Zhang, F.-H. Dai, Y. Liu, Q.-M. Wang, J.-J. Zheng, L. Xu, E. C. Holmes, Y.-Z. Zhang, A new coronavirus associated with human respiratory disease in China. Nature 579, 265-269 (2020). doi:10.1038/s41586-020-2008-3 Medline

8. G. Lu, Q. Wang, G. F. Gao, Bat-to-human: Spike features determining 'host jump' of coronaviruses SARS-CoV, MERS-CoV, and beyond. Trends Microbiol. 23, 468478 (2015). doi:10.1016/i.tim.2015.06.003 Medline

9. D. M. Knipe, P. M. Howley, Eds., Fields Virology (Lippincott Williams \& Wilkins, ed. 6, 2013).

10. A. C. Walls, Y.-J. Park, M. A. Tortorici, A. Wall, A. T. McGuire, D. Veesler, Structure, function, and antigenicity of the SARS-CoV-2 spike glycoprotein. Cell 181, 281292.e6 (2020). doi:10.1016/i.cell.2020.02.058 Medline

11. M. Hoffmann, H. Kleine-Weber, S. Schroeder, N. Krüger, T. Herrler, S. Erichsen, T. S. Schiergens, G. Herrler, N.-H. Wu, A. Nitsche, M. A. Müller, C. Drosten, S. Pöhlmann, SARS-CoV-2 cell entry depends on ACE2 and TMPRSS2 and is blocked by a clinically proven protease inhibitor. Cell 181, 271-280.e8 (2020). doi:10.1016/j.cell.2020.02.052 Medline

12. Q. Wang, Y. Zhang, L. Wu, S. Niu, C. Song, Z. Zhang, G. Lu, C. Qiao, Y. Hu, K.-Y. Yuen, Q. Wang, H. Zhou, J. Yan, J. Qi, Structural and functional basis of SARS-CoV2 entry by using human ACE2. Cell 10.1016/j.cell.2020.03.045 (2020). doi:10.1016/i.cell.2020.03.045 Medline

13. D. Wrapp, N. Wang, K. S. Corbett, J. A. Goldsmith, C.-L. Hsieh, O. Abiona, B. S. Graham, J. S. McLellan, Cryo-EM structure of the 2019-nCoV spike in the prefusion conformation. Science 367, 1260-1263 (2020). doi:10.1126/science.abb2507 Medline

14. Y. Zhou, Y. Yang, J. Huang, S. Jiang, L. Du, Advances in MERS-CoV vaccines and therapeutics based on the receptor-binding domain. Viruses 11, 60 (2019). doi:10.3390/v11010060 Medline

15. L. Du, Y. Yang, Y. Zhou, L. Lu, F. Li, S. Jiang, MERS-CoV spike protein: A key target for antivirals. Expert Opin. Ther. Targets 21, 131-143 (2017). doi:10.1080/14728222.2017.1271415 Medline

16. L. Du, Y. He, Y. Zhou, S. Liu, B.-J. Zheng, S. Jiang, The spike protein of SARS-CoVA target for vaccine and therapeutic development. Nat. Rev. Microbiol. 7, 226-236 (2009). doi:10.1038/nrmicro2090 Medline

17. Q. Wang, T. Ma, Y. Wu, Z. Chen, H. Zeng, Z. Tong, F. Gao, J. Qi, Z. Zhao, Y. Chai, H. Yang, G. Wong, Y. Bi, L. Wu, R. Shi, M. Yang, J. Song, H. Jiang, Z. An, J. Wang, T. D. Yilma, Y. Shi, W. J. Liu, M. Liang, C. Qin, G. F. Gao, J. Yan, Neutralization mechanism of human monoclonal antibodies against Rift Valley fever virus. Nat. Microbiol. 4, 1231-1241 (2019). doi:10.1038/s41564-019-0411-z Medline

18. Y. Wu, Y. Zhu, F. Gao, Y. Jiao, B. O. Oladejo, Y. Chai, Y. Bi, S. Lu, M. Dong, C. Zhang, G. Huang, G. Wong, N. Li, Y. Zhang, Y. Li, W. H. Feng, Y. Shi, M. Liang, R. Zhang, J. Qi, G. F. Gao, Structures of phlebovirus glycoprotein Gn and identification of a neutralizing antibody epitope. Proc. Natl. Acad. Sci. U.S.A. 114, E7564-E7573 (2017). doi:10.1073/pnas.1705176114 Medline

19. Z. Otwinowski, W. Minor, Processing of X-ray diffraction data collected in oscillation mode. Methods Enzymol. 276, 307-326 (1997). doi:10.1016/S0076$\underline{6879(97) 76066-X}$
20. P. Emsley, K. Cowtan, Coot: Model-building tools for molecular graphics. Acta Crystallogr. D 60, 2126-2132 (2004). doi:10.1107/S0907444904019158 Medline 21. P. D. Adams, R. W. Grosse-Kunstleve, L.-W. Hung, T. R. loerger, A. J. McCoy, N. W. Moriarty, R. J. Read, J. C. Sacchettini, N. K. Sauter, T. C. Terwilliger, PHENIX: Building new software for automated crystallographic structure determination. Acta Crystallogr. D 58, 1948-1954 (2002). doi:10.1107/S0907444902016657 Medline

22. C. J. Williams, J. J. Headd, N. W. Moriarty, M. G. Prisant, L. L. Videau, L. N. Deis, V. Verma, D. A. Keedy, B. J. Hintze, V. B. Chen, S. Jain, S. M. Lewis, W. B. Arendall 3rd, J. Snoeyink, P. D. Adams, S. C. Lovell, J. S. Richardson, D. C. Richardson, MolProbity: More and better reference data for improved all-atom structure validation. Protein Sci. 27, 293-315 (2018). doi:10.1002/pro.3330 Medline

\section{ACKNOWLEDGMENTS}

We thank the staff of the BL17U1 beamline at Shanghai Synchrotron Radiation Facility (SSRF) for data collection. We thank Dr. Honglei Sun for discussion the histopathology experiment. Funding: This work was supported by Zhejiang University special scientific research fund for COVID-19 prevention and control (2020XGZX019), the National Science and Technology Major Project (2018ZX10733403), the National Key R\&D Program of China (2018YFC1200603), the National Key Plan for Scientific Research and Development of China (2016YFD0500304), National Natural Science Foundation of China (31872745, 81902058 and 32041010), and the National Science and Technology Major Projects of Infectious Disease Funds (2017ZX10304402). Author contributions: Y.W., F.G., G.F.G. and L.L. initiated and coordinated the project. Y.W., F.G. and G.F.G designed the experiments. Y.L. and L.L. provided the convalescent PBMCs. Y.W. and C.S performed the cell sorting. W.P., C.Z, Z.L. and C.G.S. sequenced and constructed the antibodies. Y.W. conducted the SPR and Octet analysis with the help of F.Z., F.W., Z.L. and Q.W. C.S. and Y.Y. evaluated the neutralizing potency. S.L. and Y.B. conducted the animal experiments with the help from G.W., W.T., X.L., C.F., C.Z. and H.X. qRT-PCR was conducted by Y.G. F.W., W.P. D.L. C.Z. and Z.L expressed and purified proteins. J.Q. and F.G. collected the diffraction dada and determined the complex structure. Y.W., F.G. and G.F.G. analyzed the data and wrote the manuscript. S.T. revised the manuscript. Competing interests: Y.W., F.W., C.S., D.L., S.T., Y.L, G.F.G and L.L. are listed as inventors on pending patent applications for MAb B38 and $\mathrm{H} 4$. The other authors declare that they have no competing interests. Data and materials availability: The atomic coordinate for the complex of the COVID-19 virus RBD and B38 has been deposited in the Protein Data Bank (www.rcsb.org). The PDB ID code is 7BZ5. Antibody sequences beyond those in the supplementary materials are available under an MTA. This work is licensed under a Creative Commons Attribution 4.0 International (CC BY 4.0) license, which permits unrestricted use, distribution, and reproduction in any medium, provided the original work is properly cited. To view a copy of this license, visit

https://creativecommons.org/licenses/by/4.0/. This license does not apply to figures/photos/artwork or other content included in the article that is credited to a third party; obtain authorization from the rights holder before using such material.

\section{SUPPLEMENTARY MATERIALS}

science.sciencemag.org/cgi/content/full/science.abc2241/DC1

Materials and Methods

Figs. S1 to S3

Tables S1 to S4

References (19-22)

MDAR Reproducibility Checklist

13 April 2020; accepted 5 May 2020

Published online 13 May 2020

10.1126/science.abc2241 

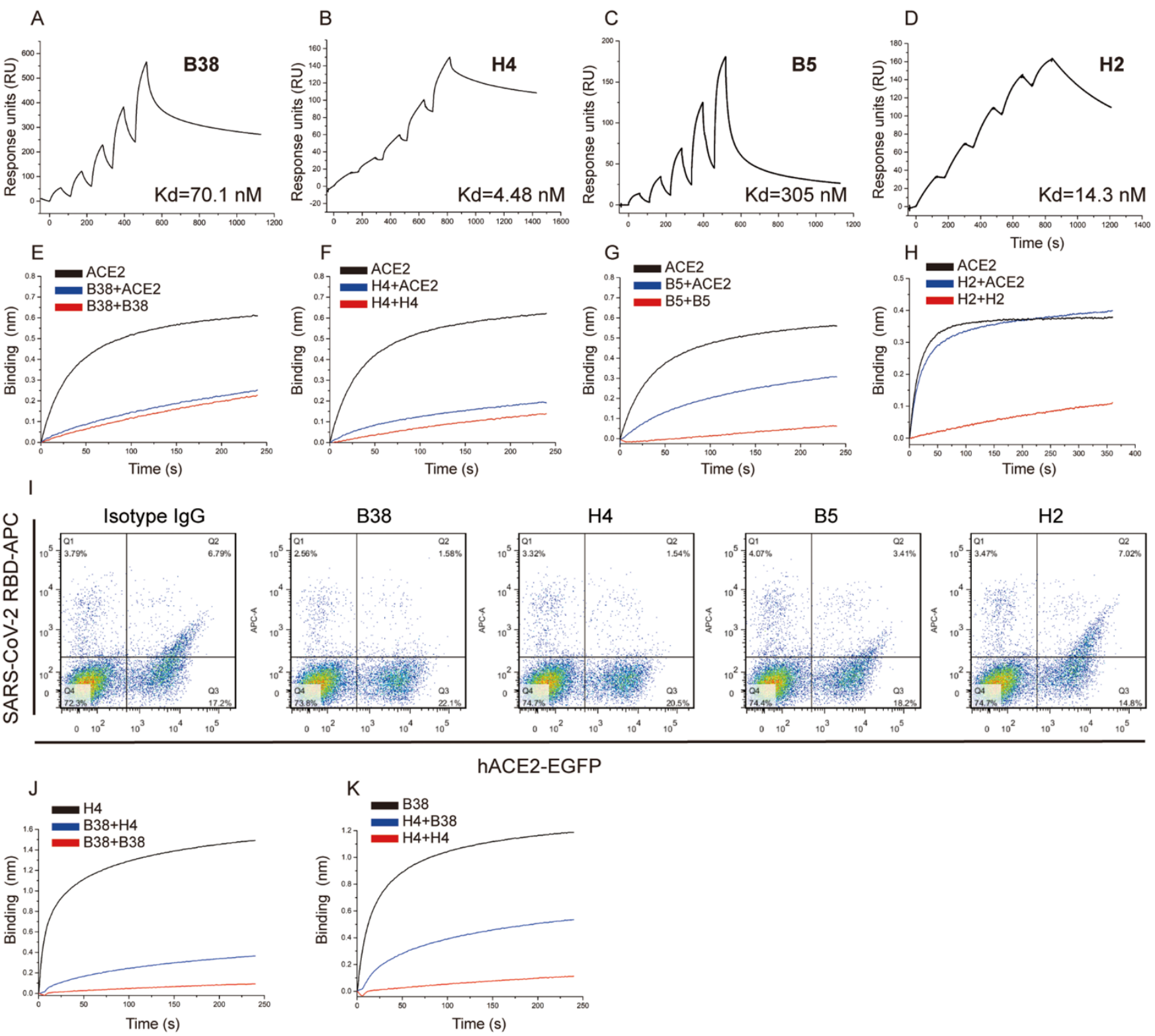

Fig. 1. Characterization of COVID-19 virus specific neutralizing antibodies. (A to D) The binding kinetics between four antibodies (B38, H4 B5 and H2) and COVID-19 virus RBD were measured using a single-cycle BIAcore $8 \mathrm{~K}$ system. (E to $\mathrm{H}$ ) Competition binding to the COVID-19 virus RBD between antibodies and ACE2 were measured by BLI. Immobilized biotinylated COVID-19 virus RBD (10 $\mu \mathrm{g} / \mathrm{mL})$ were saturated with antibodies, and then flowed with corresponding antibody in the presence of $300 \mathrm{nM}$ soluble ACE2 (blue) or without ACE2 (red). As a control, the immobilized biotinylated RBD was flowed with buffer, and then flowed with the equal molar of ACE2 (black). The grams show binding patterns after antibody saturation. (I) hACE2EGFP was expressed on the HEK293T cell surface, and the cells were stained with $200 \mathrm{ng} / \mathrm{mL}$ COVID-19 virus RBD his-tag proteins pre-incubated with isotype lgG, B38, H4, B5 or $\mathrm{H} 2$. The percentage of both antihistag $\mathrm{APC}^{+}$and $\mathrm{EGFP}^{+}$cells were calculated. ( $\mathrm{J}$ and $\mathrm{K}$ ) Competition binding to COVID-19 virus RBD between B38 and H4 was measured by BLI. Immobilized COVID-19 virus RBD (10 $\mathrm{gg} / \mathrm{mL})$ were saturated with 300 $\mathrm{nM}$ of the first antibody, and then flowed with equal molar of the first antibody in the presence of (blue) or without (red) the second antibody. Equal molar of the second antibody flowed on the immobilized RBD as a control (black). The grams show binding patterns after saturation of the first antibody. 

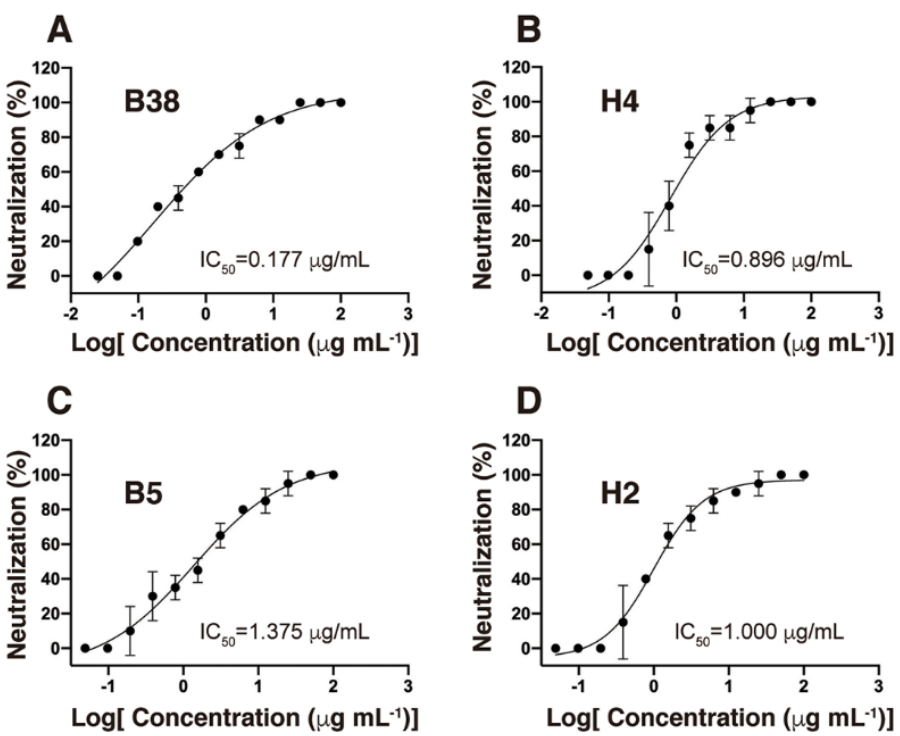

E

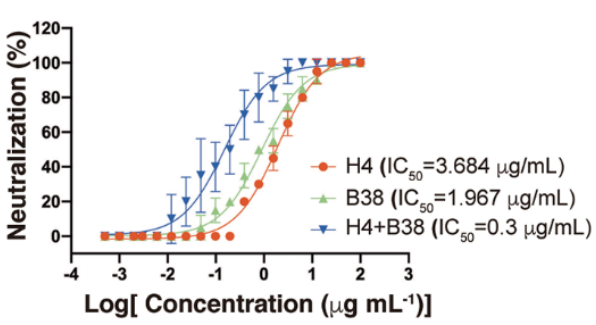

Fig. 2. Four antibodies can effectively neutralize COVID-19 virus, and two of them exhibit additive inhibition effect. The mixtures of COVID-19 virus and serially diluted antibodies were added to Vero E6 cells. After 5 days incubation, $I C_{50}$ were calculated by fitting the CPE from serially diluted antibody to a sigmoidal dose-response curve. The $\mathrm{IC}_{50}$ were labeled accordingly. 100 TCID50 and 200 TCID50 of COVID-19 virus were used for testing the neutralizing abilities of individual antibody (A to D) and cocktail antibodies (E), respectively. 
A

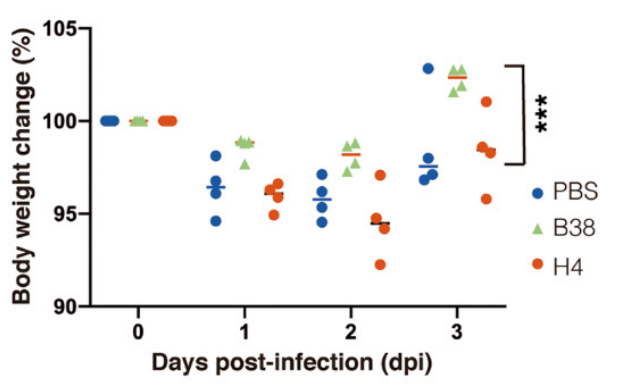

PBS
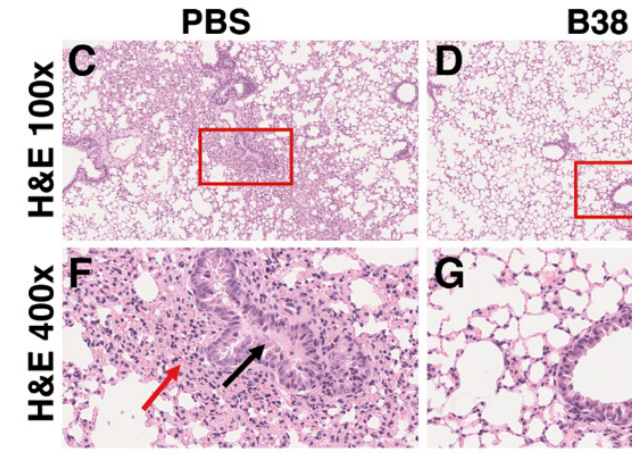

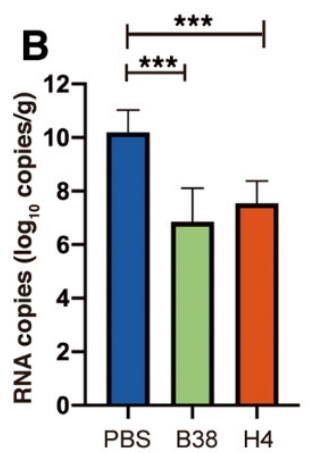

H4

Fig. 3. The protection efficiency of MAbs in hACE2 mice model post infection with COVID-19 virus. (A) Body weight loss were recorded for PBS $(n=4)$, B38 treatment $(n=4)$ and H4 treatment $(n=4)$ groups. All the mice were challenged intranasally with COVID-19 virus, and $25 \mathrm{mg} / \mathrm{kg}$ antibodies were injected (i.p.) 12 hours post-infection. Equal volume of PBS was used as a control. The weight loss was recorded over three days, and the significant difference can be observed between B38 group and PBS group (unpaired $t$-test, ${ }^{* *} p<0.001$ ). (B) The virus titer in lungs of three groups were determined at 3 dpi by qRT-PCR. The MAb treatment group can reduce the viral load in the lung of mice (unpaired $t$-test, ${ }^{* * *} p<0.001$ ). ( $\mathrm{C}$ to $\left.\mathrm{H}\right)$ Representative histopathology of the lungs in COVID-19 virus infected hACE2 mice $(3 \mathrm{dpi})$. Severe bronchopneumonia and interstitial pneumonia can be observed in the PBS group $[(C)$ and $(F)]$, with edema and bronchial epithelia cell desquamation (black arrow) and infiltration of lymphocytes within alveolar spaces (red arrow). Mild bronchopneumonia was observed in the $\mathrm{H} 4$ group [(E) and $(\mathrm{H})]$, while no lesions have been observed in the B38 group [(D) and $(G)]$. The images and areas of interest are $100 \times$ and $400 \times$. 

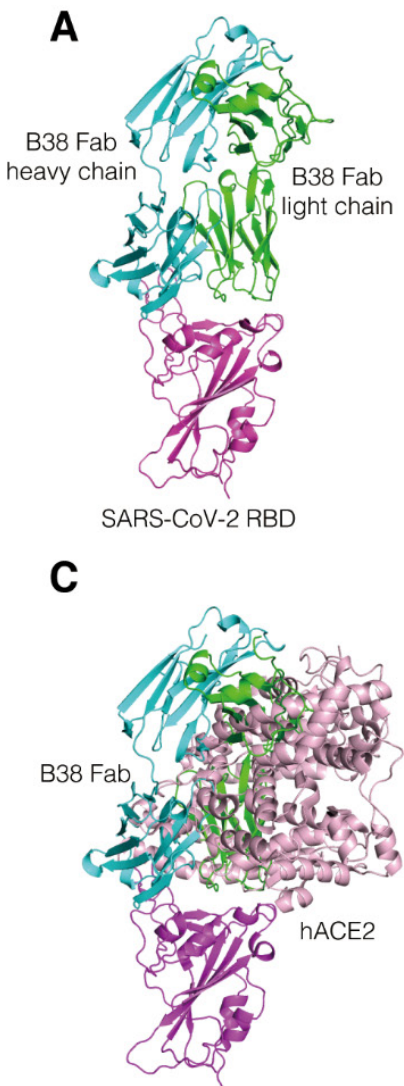

SARS-CoV-2 RBD

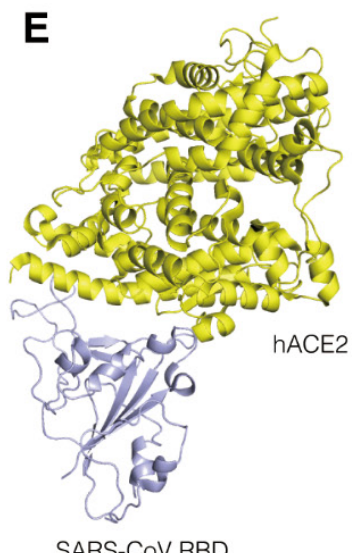

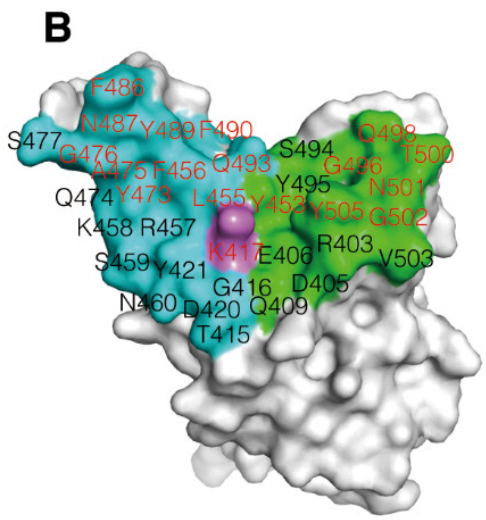

D

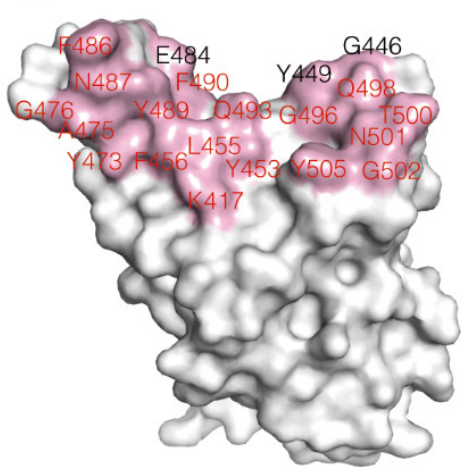

$\mathbf{F}$

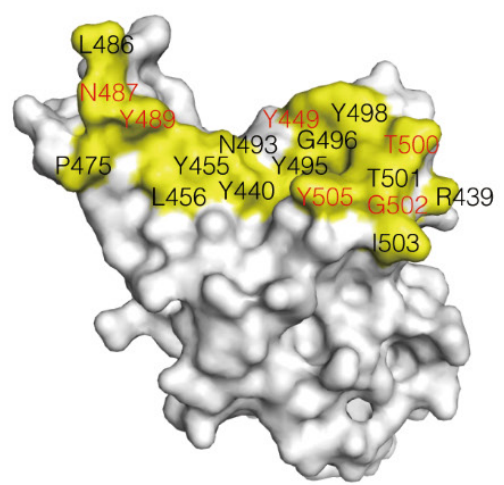

G

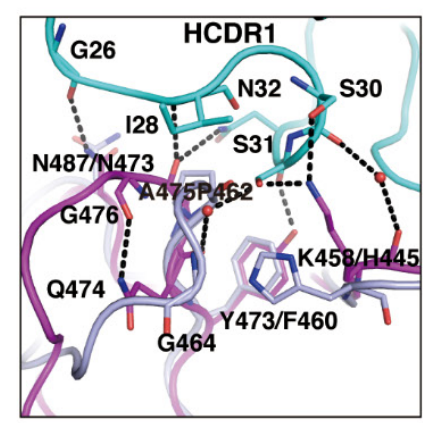

I

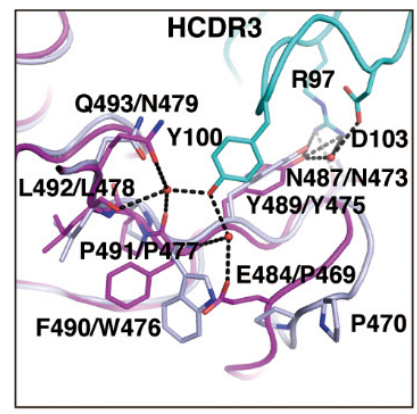

$\mathbf{J}$

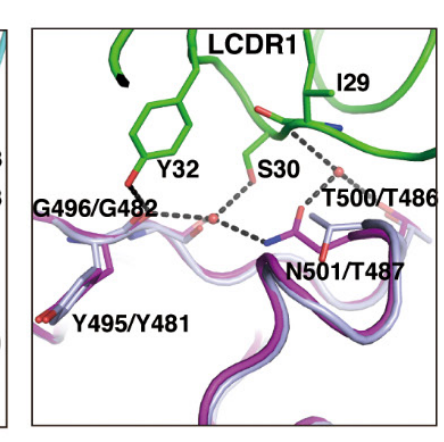

H

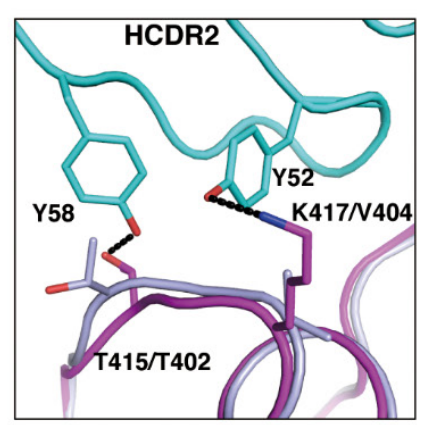

K

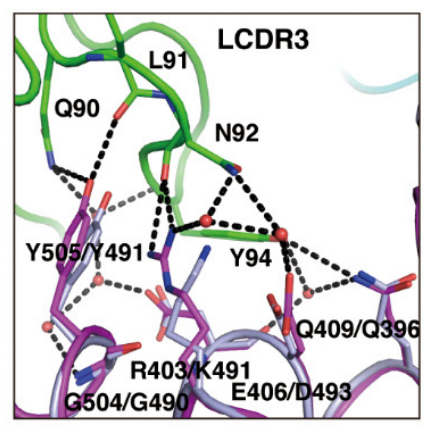

Fig. 4. Structural analysis of B38 and COVID-19 virus RBD complex and the epitope comparison between B38 and hACE2. (A) The overall structure of B38 Fab and COVID-19 virus RBD. The B38 heavy chain (cyan), light chain (green) and COVID-19 virus RBD (magenta) are displayed in cartoon representation. (B) The epitope of B38 are shown in surface representation. The contact residues by heavy chain, light chain or both are colored in cyan, green and magenta. The identical residues on RBD involved in B38 and hACE2 binding are labeled in red. (C) Superimposition of B38/COVID-19 virus RBD and hACE2/COVID-19 virus RBD (PDB: $6 \mathrm{LZG}$ ). All the molecules are presented in cartoon, with the same colors in Fig. 3A. hACE2 is colored in light pink. (D) The residues involved in hACE2-RBD binding are highlighted in light pink. The identical residues on RBD involved in B38 and hACE2 binding are labeled in red. (E) The complex structure of SARS-CoV RBD (light blue) and hACE2 (yellow) (PDB:2AJF). (F) The residues in contact with hACE2 are colored in yellow. The residues are numbered according to SARS-CoV RBD. The identical residues involved in hACE2 binding of two RBDs are labeled in red. (G to I) The detailed interactions between COVID-19 virus RBD and CDR loops of heavy chain. ( $\mathrm{J}$ and $\mathrm{K}$ ) The detailed interactions between COVID-19 virus RBD and CDR loops of light chain. The residues are shown in sticks with the identical colors to Fig. 3C. The water molecules are displayed in red sphere. 